\title{
PELATIHAN PENYUSUNAN LAPORAN KEUANGAN UNTUK UMKM KABUPATEN KARAWANG
}

\author{
Yeny Rostiani ${ }^{1}$, Indaryono ${ }^{2}$, Arif Maulana Yusuf ${ }^{3}$, Donny Apdian ${ }^{4}$ \\ 1,2,3,4Program Studi Komputerisasi Akuntansi, STMIK ROSMA \\ Email : ${ }^{1}$ yeny@rosma.ac.id, ${ }^{2}$ indaryono@dosen.rosma.ac.id, ${ }^{3}$ arif@rosma.ac.id, \\ ${ }^{4}$ donny@dosen.rosma.ac.id \\ Diterima : 14-06-2021, Di publikasikan : 16-06-2021
}

\begin{abstract}
Abstrak
Usaha Mikro Kecil dan Menengah(UMKM) menyumbang pendapatan daerah. Pertumbuhan UMKM di Kabupaten Karawang berkembang dengan pesat. Untuk dapat meningkatkan pendapatan daerah, UMKM perlu pembimbingan dalam pelaporan keuangan yang terkait dengan pelaporan pajak serta keikutsertaan dalam program - program Dinas Koperasi dan UMKM. Pelatihan penyusunan laporan keuangan menjadi salah satu strategi meningkatkan pemahaman pelaku usaha, sehingga dapat berdampak pada peningkatan pendapatan daerah. Pada kegiatan ini, mitra dari pelatihan penyusunan laporan keuangan adalah UMKM yang ada berdomisili di Kabupaten Karawang. Pelaksanaan ini didukung oleh Dinas Koperasi dan UMKM Kabupaten Karawang. Kegiatan ini diawali dengan kerjasama mitra yaitu asosiasi UMKM Kabupaten Karawang, kemudian dilakukan penjadwalan kegiatan dan pelaksanaan kegiatan. Hasil dari kegiatan ini adalah peserta mampu menyusun laporan keuangan yang standar dan dapat dipergunakan untuk pelaporan pajak. Kegiatan ini dapat memberikan dampak yang kepada pemerintah daerah Kabupaten Karawang.
\end{abstract}

Kata Kunci : Laporan Keuangan, Penyusunan, UMKM.

Abstract

Micro, Small and Medium Enterprises (MSMEs) contribute to regional income. The growth of MSMEs in Karawang Regency is growing rapidly. To be able to increase regional income, MSMEs need guidance in financial reporting related to tax reporting and participation in the programs of the Cooperatives and MSMEs Office. Training in the preparation of financial reports is one of the strategies to increase the understanding of business actors, so that it can have an impact on increasing regional income. In this activity, the partners of the training in preparing financial reports are MSMES who are domiciled in Karawang Regency. This implementation is supported by the Department of Cooperatives and SMEs Karawang Regency. This activity begins with partner collaboration, namely the Karawang Regency MSME association, then scheduling activities and implementing activities. The result of this activity is that participants are able to prepare standard financial reports that can be used for tax reporting. This activity can have an impact on the local government of Karawang Regency.

Keyword : Financial Reports, Preparation, SMEs. 


\section{PENDAHULUAN}

Pesatnya pertumbuhan UMKM di Kabupaten Karawang, mendukung peningkatan pendapatan daerah. Tempo.co melaporkan bahwa ada sebanyak 87.574 pelaku UMKM pada tahun 2020(Tempo.co, 2021)(Express, 2021)(Center, 2021). Kabupaten sebagai penyangga Ibu Kota, termasuk pada kota di industri. Tentunya, ini merupakan faktor positif yang patut terus dikembangkan dalam rangka meningkatkan perekonomian daerah(Hartelina, 2019).

Strategi pengembangan ini dapat dilakukan dengan memberikan pendampingan kepada UMKM agar tetap berkembang dan meningkatkan pertumbuhan jenis - jenis UMKM lain yang dapat berpotensi di minati oleh masyarakat. Pembinaan yang dapat dilakukan untuk dapat mengetahui tingkat produktivitas UMKM dapat dilakukan melalui pembinaan pajak. Pembinaan pajak dapat diambil dari laporan keuangan UMKM yang dilaporkan oleh pelaku usaha setiap tahunnya.

Namun tidak banyak pelaku usaha yang memahami bagaimana menyusun laporan keuangan. Karena rata - rata pelaku usaha memiliki keterbatasan sumber daya manusia dan keterbatasan pengetahuan tentang pengelolaan keuangan. Pada kegiatan ini, mitra pelatihan laporan keuangan adalah UMKM yang berdomisili di Kabupaten Karawang. Tujuan dari kegiatan ini adalah meningkatkan pemahaman tentang tata cara penyusunan laporan keuangan sesuai standar yang dapat di laporkan pada saat pelaporan pajak tahunan. Dalam kegiatan ini, didukung oleh asosiasi UMKM Kabupaten Karawang dan Dinas Koperasi dan UMKM Karawang.

Beberapa peneliti mengungkapkan bahwa kegiatan pelatihan penyusunan laporan keuangan mendukung pemahaman tentang pelaporan pajak. Berikut adalah sumber - sumber yang mengungkap pernyataan tersebut (Rayyani, Abdi, Winarsi, \& Warda, 2020), (Syahrenny, 2019),(Wijayanti, 2020), (Darmawati, Dizar, \& Harahap, 2020), (Darmawati et al., 2020). Berdasarkan sumber tersebut, beberapa menyatakan bahwa pendampingan dan pelatihan dapat meningkatkan produktivitas UMKM.

\section{METODE}

Kegiatan pelatihan penyusunan laporan keuangan ini dilakukan dengan prosedur diantaranya diawali dengan penandatangan kerjasama dengan asosiasi UMKM di Kabupaten Karawang. Kemudian dilanjut dengan perijinan untuk dukungan acara kepada Dinas Koperasi dan UMKM. Sebelum pelaksanaan dilakukan penyusunan materi yang dikhususkan untuk peningkatan pengetahuan penyusunan laporan keuangan untuk usaha dagang. Pelaksanaan kegiatan dilakukkan di STMIK ROSMA dengan jumlah peserta sebanyak 50 peserta dari pelaku usaha. 
Pemateri dari kegiatan ini adalah dosen dari program studi Komputerisasi Akuntansi STMIK ROSMA.

\section{HASIL DAN PEMBAHASAN}

Kegiatan pelatihan penyusunan laporan keuangan bagi UMKM di Kabupaten Karawang di laksanakan pada tanggal 21 Oktober 2020. Kegiatan ini dibuka oleh Kepala Dinas Koperasi dan UMKM Kabupaten Karawang dan Ketua STMIK ROSMA Karawang. Pada acara pembukaan, Kepala Dinas memberikan arahan pentingnya pelaporan keuangan oleh UMKM pada saat pelaporan pajak. Sedangkan Ketua STMIK ROSMA lebih mengarahkan bagaimana kegiatan ini dapat berkelanjutan dan STMIK ROSMA dapat menjadi konsultan bagi UMKM Karawang dalam hal penyusunan laporan pajak.

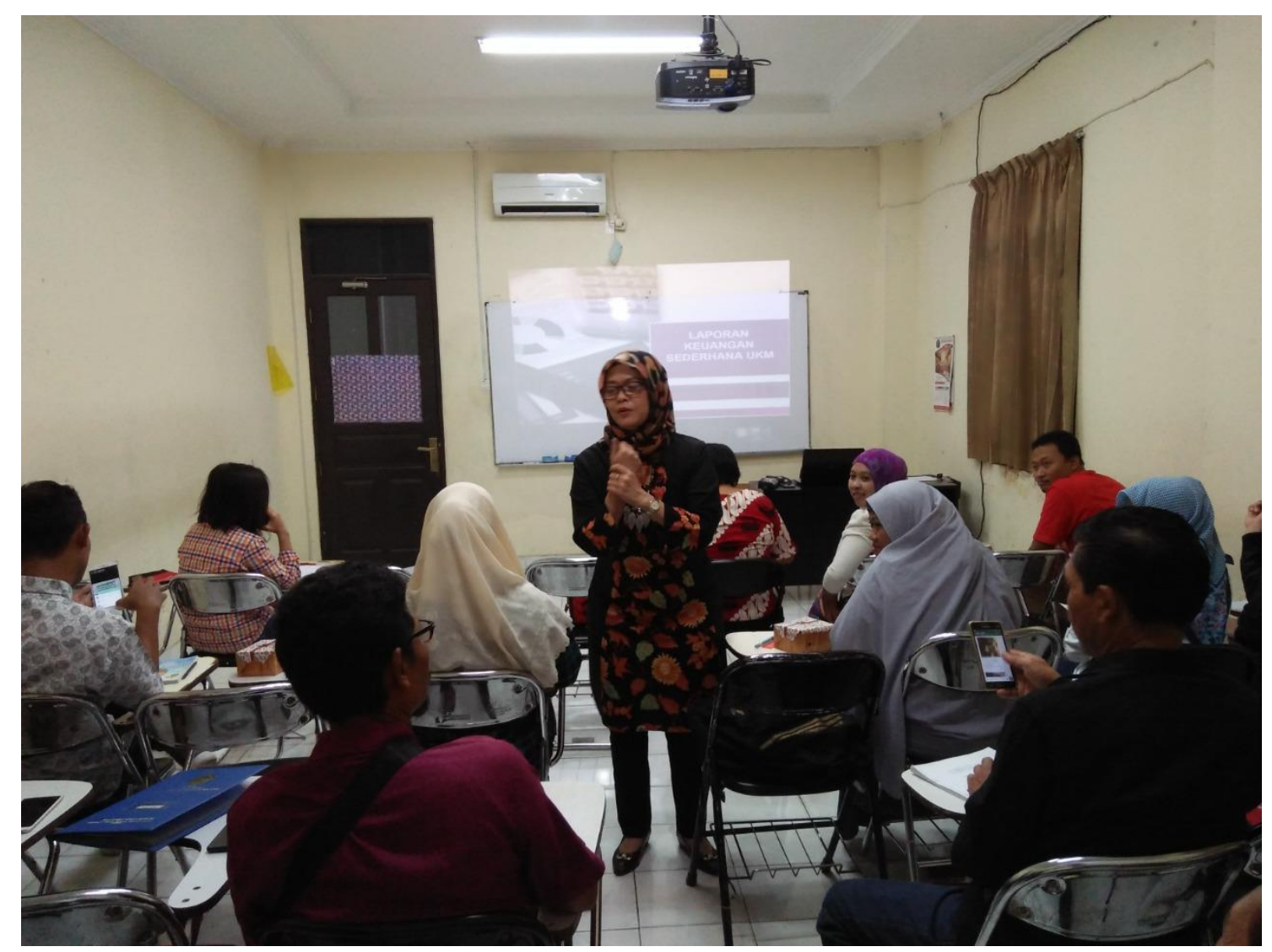

Gambar 1. Pemateri memulai sesi pertama 


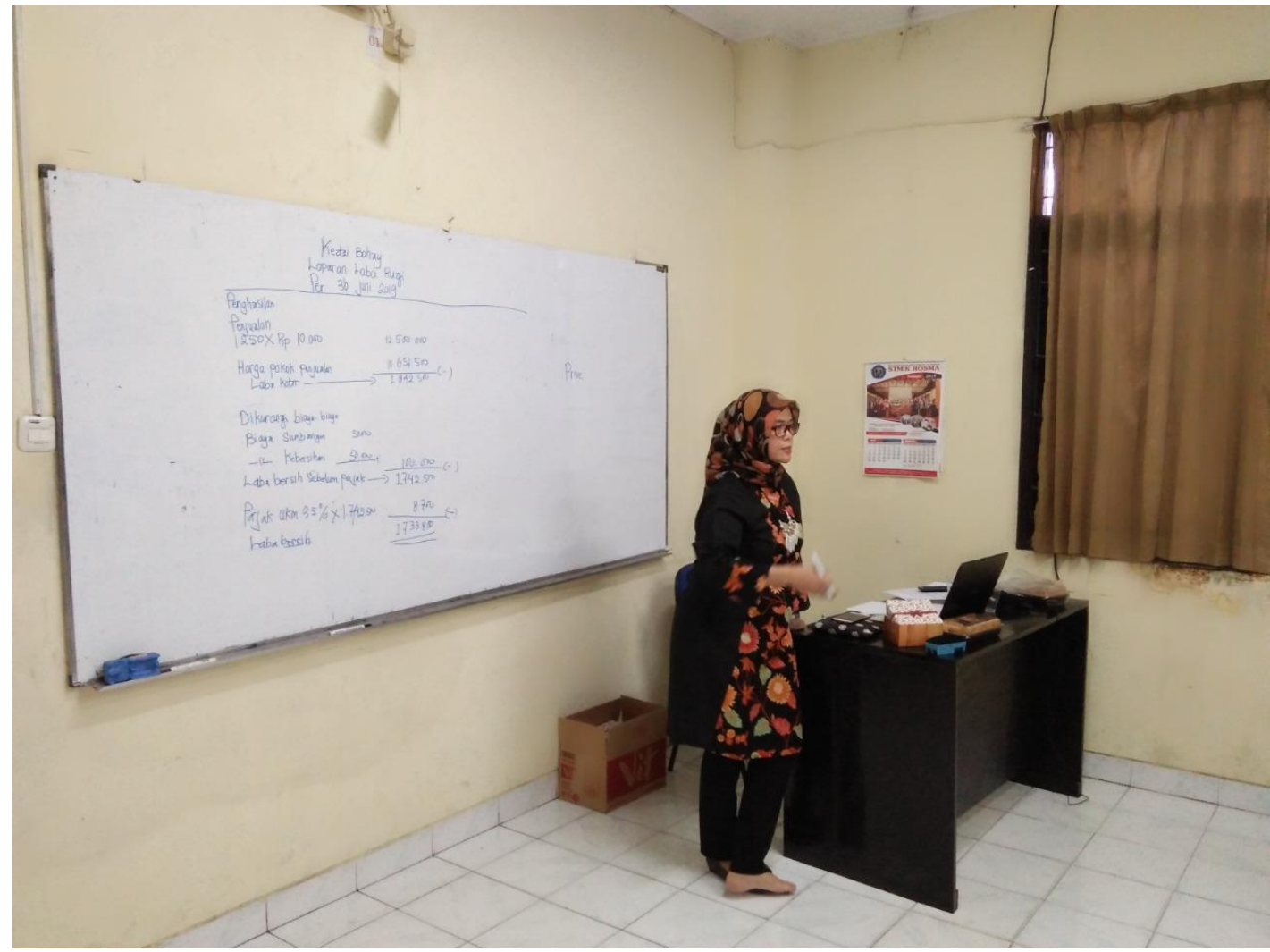

Gambar 2. Pemateri menyajikan contoh perhitungan dalam laporan keuangan

Memasuki acara inti, Dosen dari program studi Komputerisasi Akuntansi mulai memaparkan deskripsi dari laporan keuangan, jenis - jenisnya serta langkah - langkah yang dilakukan dalam penyusunan laporan. Pada setiap pergantian materi, seluruh peserta diberikan kesempatan untuk bertanya terkait materi. Beberapa pertanyaan yang terlontar, merupakan hal - hal yang biasa di hadapi oleh UMKM ketika akan menyusun laporan keuangan. Pada sesi kedua kegiatan ini, para pelaku usaha(peserta pelatihan) diberikan kesempatan untuk mengimplemtasikan laporan keuangan berdasarkan usaha mereka. Ketika proses implemtasi, terlihat banyak pelaku usaha masih kesulitan memami tentang pembagian akun - akun pada pelaporan. Namun, dalam pelatihan ini, dua pemateri membimbing dan mendamping para peserta, sehingga para peserta dapat langsung memahami dan mengkoreksi kesalahan dari penyusunan yang telah dilakukan. Pada sesi terakhir, pemateri juga menyisipkan cara - cara beberapa template laporan keuangan dalam bentuk Microsoft office excel, yang mudah untuk di pahami, sehingga tidak memerlukan kalkulasi. Antusias peserta pelatihan, sangat terlihat ketika mereka berhasil mengimplementasikan laporan keuangan mereka kedalam template excel yang disajikan oleh pemateri. 


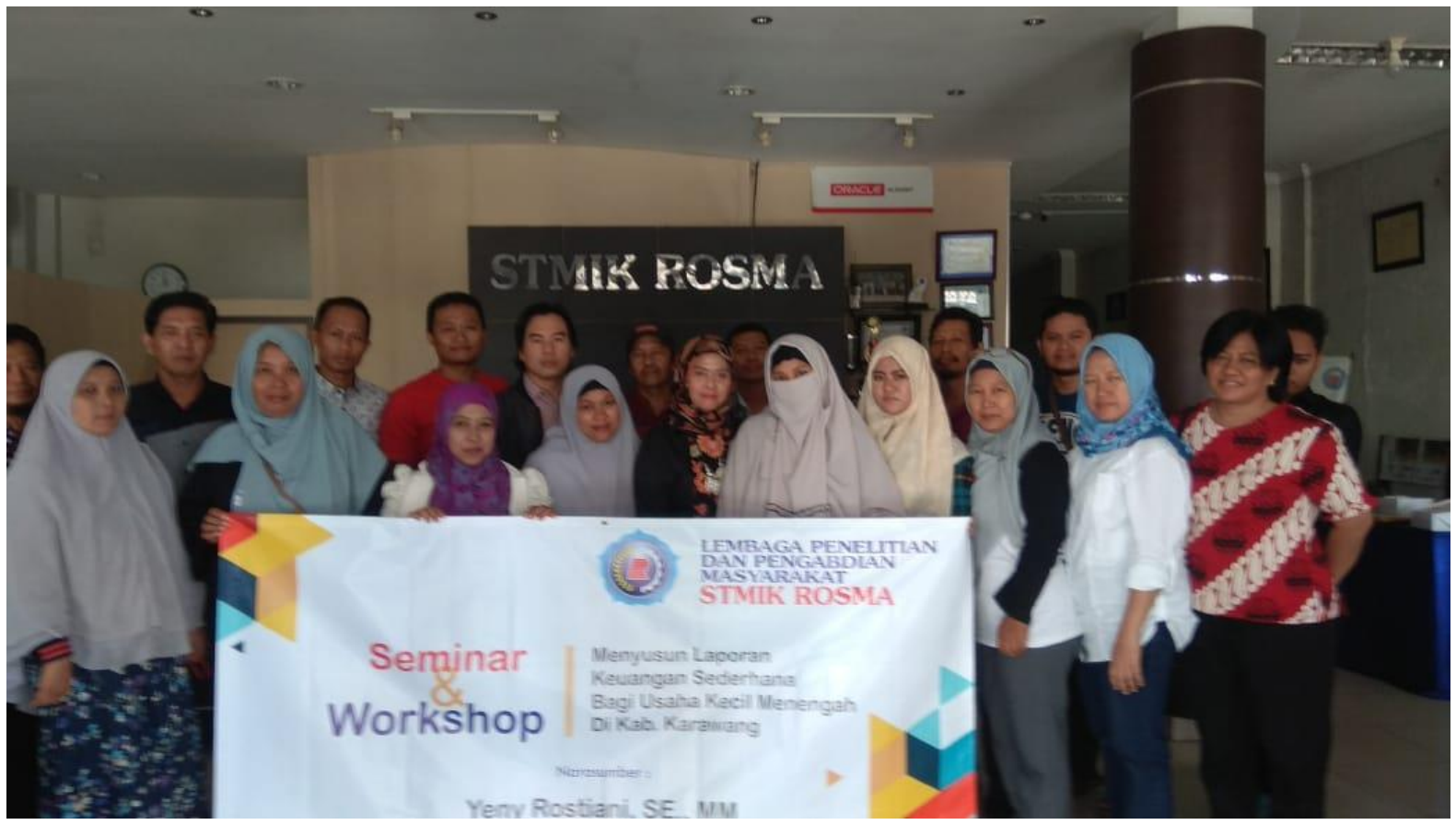

Gambar 3. Sesi foto bersama setelah kegiatan

\section{KESIMPULAN DAN SARAN}

Pelatihan penyusuan laporan keuangan untuk UMKM di Kabupaten Karawang, dilaksanakan dengan lancar dan penuh antusias dari para peserta. Hasil dari pelatihan ini, adalah peningkatan pemahaman terkait penyusunan pelaporan keuangan oleh pelaku usahan di Kabupaten Karawang. Kegiatan ini dapat berimplikasi kepada pendapatan daerah, karena pelaku usaha dapat melaporkan produktivitasnya setiap tahun, baik melalui laporan pajak atau pendataan dari Dinas Koperasi dan UMKM. Dengan pelaporan tersebut, pemerintah daerah Karawang dapat memonitoring perkembangan produktivitas UMKM.

\section{UCAPAN TERIMA KASIH}

Ucapan terima kasih disampaikan kepada STMIK ROSMA yang telah memberikan ruang kepada terlaksananya kegiatan. Terimakasih kepada Asosiasi UMKM Kabupaten Karawang dan Dinas Koperasi dan UMKM Kabupaten Karawang yang telah bersedia memfasilitasi kegiatan ini. 


\section{REFFERENCE}

Center, K. (2021). UMKM Kabupaten Karawang. Retrieved June 9, 2021, from Karawang Center website: https://news.karawang.center/kantor-dinas-koperasi-dan-umkmkarawang-87-574-umkm-di-karawang-terdaftar-bantuan-modal-rp24-juta.html

Darmawati, D., Dizar, S., \& Harahap, C. D. (2020). Peningkatan Efektivitas Penyusunan Laporan Keuangan Sederhana Bagi Himpunan Pengusaha Laundry Indonesia (Hipli). Jurnal Berdaya Mandiri, 2(2), 366-375. https://doi.org/10.31316/jbm.v2i2.696

Express, P. (2021). UMKM Kabupaten Terdampak Covid. Retrieved June 9, 2021, from Pasundan Express website: https://www.pasundanekspres.co/jabar/karawang/sebanyak-87-574-pelaku-umkm-dikarawang-terdampak-covid-19/

Hartelina. (2019). Orientasi Pasar Pada UMKM Di Kabupaten Karawang. FRIMA- Festival Riset IImiah Manajemen Dan Bisnia, 697-713.

Rayyani, W. O., Abdi, M. N., Winarsi, E., \& Warda, W. (2020). Peningkatan Daya Saing UMKM Melalui Optimalisasi Penyusunan Laporan Keuangan. Jurnal Dedikasi Masyarakat, 3(2), 97-105.

Syahrenny, N. (2019). LAPORAN KEUANGAN UMKM SESUAI SAK EMKM Nenny Syahrenny. Seminar Nasional Penelitian Dan Pengabdian Masyarakat, 13-17.

Tempo.co. (2021). UMKM Kabupaten Karawang. Retrieved June 9, 2021, from Tempo.co website: https://metro.tempo.co/read/1404452/87-574-umkm-di-karawang-terdaftarmenerima-bantuan-modal/full\&view=ok

Wijayanti, R. (2020). Pelatihan Penyusunan Laporan Keuangan pada Usaha Dagang Sahadewa Batik. Proceeding of The URECOL, (2012), 112-116. Retrieved from http://repository.urecol.org/index.php/proceeding/article/view/1113 